\title{
Animal models of interferon signature positive lupus
}

\author{
Haoyang Zhuang ${ }^{1}$, Christopher Szeto ${ }^{1}$, Shuhong Han ${ }^{1},{\text { Lijun } \text { Yang }^{2} \text { and }}^{2}$ \\ Westley H. Reeves ${ }^{1 *}$ \\ ${ }^{1}$ Division of Rheumatology and Clinical Immunology, Department of Medicine, University of Florida, Gainesville, FL, USA, \\ ${ }^{2}$ Department of Pathology, Immunology, and Laboratory Medicine, University of Florida, Gainesville, FL, USA
}

\section{OPEN ACCESS}

Edited by:

Kenneth Michael Pollard,

The Scripps Research Institute, USA

Reviewed by:

Ching Chen,

University of Maryland School of

Medicine, USA

Dwight Kono,

The Scripps Research Institute, USA

*Correspondence:

Westley H. Reeves,

Division of Rheumatology and Clinical Immunology, University of Florida,

PO Box 100221, Gainesville, FL 32610-0221, USA whreeves@ufl.edu

Specialty section:

This article was submitted to $B$ Cell Biology, a section of the journal

Frontiers in Immunology

Received: 12 February 2015 Accepted: 20 May 2015

Published: 05 June 2015

Citation:

Zhuang $H$, Szeto C, Han S, Yang L and Reeves WH (2015) Animal models of interferon signature positive lupus.

Front. Immunol. 6:291.

doi: 10.3389/fimmu.2015.00291
Human lupus is strongly associated with a gene expression signature characterized by over-expression of Type I interferon-regulated genes. A strong interferon signature generally is not seen in the standard mouse models of lupus, despite considerable evidence for the involvement of toll-like receptor-driven interferon production. In contrast, pristane-induced lupus exhibits a prominent TLR7-dependent interferon signature. Importantly, genetic disorders with dysregulated interferon production in both human beings and mice cause severe autoinflammatory diseases but not the typical manifestations of lupus, suggesting that interferon over-production is insufficient to cause systemic lupus erythematosus itself. Single-gene models in mice suggest that lupus-like disease may result from abnormalities in B-cell activation and the clearance of dead cells. Pristane may mimic human systemic lupus erythematosus by causing synergistic abnormalities in interferon production along with defective clearance of apoptotic cells and over-active B-cell signaling.

Keywords: interferon alpha, lupus erythematosus, systemic, animal models, toll-like receptors, pristane, apoptosis, B-cell activation

Systemic lupus erythematosus (SLE) is defined by a complex clinical syndrome (e.g., arthritis, skin rashes, oral ulcers, serositis, glomerulonephritis, nervous system involvement) and the production of antinuclear antibodies (ANAs) such as anti-Sm and anti-double-stranded (ds) DNA $(1,2)$. It has become increasingly clear that over-production of Type I interferon (IFN-I) is strongly associated with SLE and that this cytokine is involved in disease pathogenesis. Over-expression of a group of interferon-stimulated genes (ISGs) by peripheral blood mononuclear cells from SLE patients is termed the interferon signature $(3,4)$. This gene expression program is seen in over twothirds of adult and nearly all pediatric SLE patients who are defined by four or more of the ACR Classification Criteria (2). Adults exhibiting the interferon signature have an increased frequency of autoantibodies against dsDNA, Sm, RNP, and Ro, lower complement levels, and a higher frequency of lupus nephritis and possibly cutaneous manifestations than interferon signature negative patients (5-7).

Polymorphisms of a number of genes have been identified by genome-wide association studies (GWAS) to be linked to disease susceptibility in human beings, and some, such as IRF-5, are linked to the regulation of IFN-I production $(8,9)$. Additionally, therapeutic use of IFN $\alpha$ and trisomy of the Type I IFN gene cluster are associated with lupus-like autoimmunity in human beings (10, 11). However, despite the strong association of IFN-I over-production with SLE and evidence that the severity of lupus-like disease usually is attenuated in mice lacking the Type I interferon receptor (IFNAR) $(12,13)$, our understanding of the relationship of IFN-I to SLE pathogenesis is incomplete. Animal models may help address several questions, including: (1) Why do only a few patients (one of 987 in one study) treated with IFN $\alpha$ develop lupus (14)? (2) Why does IFN $\alpha$ 
induce lupus-like manifestations, whereas IFN $\beta$ generally does not (10)? (3) Why does treatment with neutralizing antibodies against IFN $\alpha$ (e.g., rontalizumab) lead to improvement of lupus in the interferon signature negative subset but not in the interferon signature high subset (15)? (4) Why do children with "interferonopathies," who are identified by the presence of a strong interferon signature, develop vasculopathy, nervous system disease, and other inflammatory manifestations but only rarely lupus (16, 17)? (5) Why do Stimulator of IFN Genes (STING)-deficient lupus mice paradoxically develop more severe lupus-like disease than controls, despite the fact that human gain-of-function mutations are associated with inflammatory disease and a high interferon signature $(18,19)$ ? (6) Why does IFN-I protect MRL/lpr mice from lupus, while exacerbating it in other strains (20)? (7) How is IFN-I linked to the production of lupus-specific autoantibodies?

\section{Interferon in Spontaneous Lupus Models}

Several mouse strains develop spontaneous lupus-like disease, but they usually do not develop sufficient clinical/serological manifestations to meet the criteria used to classify human SLE (2) (Table 1). The most-studied strains are $(\mathrm{NZB} \times \mathrm{NZW}) \mathrm{F} 1$ $(\mathrm{NZB} / \mathrm{W}), \mathrm{NZM} 2410$ and related strains (inbred derivatives of $\mathrm{NZB} / \mathrm{W}$ selected for nephritis), MRL/lpr, and BXSB male mice, although this is not a complete list. Other strains, some with single-gene defects, develop more limited lupus-like disease (see below). It is probably not appropriate to equate the production of ANAs or anti-dsDNA autoantibodies, even in the presence of glomerular immune deposits (IgG/IgM or C3 staining), with what would be defined as "SLE" in human beings by standard clinical criteria (2). Nevertheless, partial lupus-like syndromes in mice may provide important insights into the pathogenesis of the individual manifestations of SLE and the spontaneous models have the advantage that as in human SLE, genetic susceptibility factors are important. However, since the candidate susceptibility loci identified in mice often do not appear to be major factors in human SLE, it is necessary to carefully relate these models to clinical subsets of human SLE. This review focuses on the suitability of mouse models for studying the interferon signature positive subset of SLE, which as noted above is characterized clinically by the production of specific autoantibodies with an increased prevalence of nephritis and possibly cutaneous manifestations.

\section{NZB/W and NZM}

NZB/W and NZM (NZM2410, NZM2328, others) mice are similar, developing severe glomerulonephritis and anti-dsDNA autoantibodies without other clinical or serological manifestations of lupus (21) (Table 1). Anti-Sm/RNP autoantibodies are absent. We have found that they exhibit a weak interferon signature at 6 months and but not at 2 months of age (Szeto, et al., manuscript in preparation). As in human beings, NZB/W lupus is exacerbated by IFN-I over-expression with accelerated anti-dsDNA autoantibody production, increased proteinuria, and worse glomerulonephritis (22). NZB mice develop severe IFNARdependent autoimmune hemolytic anemia but otherwise have only mild lupus-like manifestations (12). It is not known whether or not they exhibit an interferon signature.

\section{MRL $+/+$ and MRL/Ipr}

MRL+/+ develop late-onset, mild, lupus-like disease, manifested primarily by autoantibody production (Table 1). Deficiency of Fas (lpr mutation) greatly accelerates the onset of anti-Sm and anti-dsDNA/chromatin autoantibodies, as well as severe glomerulonephritis in MRL/lpr mice. MRL/lpr mice do not develop antiRNP autoantibodies, although they are strongly anti-Sm positive. In contrast to $\mathrm{NZB} / \mathrm{W}, \mathrm{MRL}+/+$ and $\mathrm{MRL} /$ lpr mice do not show evidence of IFN-I over-production at 2 or 6 months of age (Szeto, et al., manuscript in preparation). In sharp contrast to the IFN-dependent disease in NZB/W, IFNAR deficiency exacerbates autoantibodies and nephritis in MRL/lpr mice (20). Paradoxically, although lupus-like disease is very mild in B6/lpr mice, autoantibody production is attenuated by IFNAR deficiency (23). Thus, background genes unique to MRL vs. B6 may play a major role in determining the phenotype of lupus-like disease and its IFN-I dependence.

\section{BXSB Male}

Although human and most spontaneous murine lupus is more common and frequently more severe in females, development of lupus in BXSB mice is limited to males (Table 1). This is due to the presence of two active copies of TLR7 (one on the $\mathrm{X}$-chromosome and another on the Y-chromosome) $(24,25)$. Male BXSB mice develop anti-dsDNA and RNA autoantibodies with nephritis. Female mice with only one active copy of TLR7 are protected. Increasing the copy number of TLR7 in B6 mice also

TABLE 1 | Selected animal models of SLE.

\begin{tabular}{|c|c|c|c|c|c|}
\hline Animal model ${ }^{\mathrm{a}}$ & IFN signature & Anti-DNA & Anti-Sm/RNP & Clinical $^{b}$ & SLE criteria ${ }^{c}$ \\
\hline NZB/W, NZM2410 & Weak & Yes & No & ANAs, severe LN & 3 \\
\hline MRL//pr & Absent & Yes & Yes & ANAs, severe LN, arthritis, skin rash? & 6 \\
\hline $\mathrm{MRL}+/+$ & Absent & Low (late) & Yes (late) & ANAs & 2 \\
\hline $\mathrm{B} 6 / / \mathrm{pr}$ & Absent & No & No & ANAs & 1 \\
\hline BXSB male & $\mathrm{N} / \mathrm{A}$ & Yes & No & ANAs, severe LN & 3 \\
\hline BAFF Tg & $\mathrm{N} / \mathrm{A}$ & Yes & No & ANAs, LN & 3 \\
\hline MerTK KO & $\mathrm{N} / \mathrm{A}$ & Yes & No & ANAs, LN, arthritis & 4 \\
\hline Pristane & Strong & Yes & Yes & ANAs, LN, arthritis, DAH, anemia, serositis & 8 \\
\hline
\end{tabular}

${ }^{a} \mathrm{Tg}$, transgenic; $K O$, knockout; N/A, not available.

${ }^{b}$ ANAs, antinuclear antibodies; LN, lupus nephritis; DAH, diffuse alveolar hemorrhage.

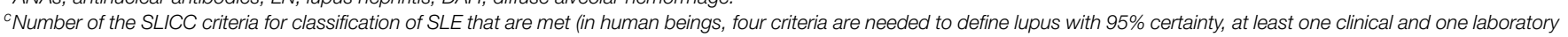
criteria). 
increases the production of anti-RNA autoantibodies (26). BXSB male mice produce high levels of anti-dsDNA antibodies and anti-RNA antibodies, but not anti-Sm/RNP. They also develop severe nephritis. It is not known whether they exhibit an interferon signature.

\section{Role of Endogenous TLR7 and TLR9 Ligands in IFN-I Production}

The endosomal toll-like receptors (TLRs) TLR7 and TLR9 promote IFN-I production via a signaling pathway involving the adapter protein MyD88, kinases (IRAK1, IRAK4, TRAF6, TRAF3, and TAK1), and the transcription factor IRF7 (27). Although there is some flexibility in the optimal stimulatory sequences, TLR7/TLR8 and TLR9 are receptors for AU-rich single-stranded RNA and non-methylated cytosine-guanosine $(\mathrm{CpG})$ motifs in DNA, respectively (28). Although they evolved as pattern recognition receptors for microbial nucleic acids, they can recognize endogenous nucleic acids, including U1 RNA (RNA component of U1 small ribonucleoproteins, recognized by anti-Sm/RNP autoantibodies) and certain endogenous DNA motifs (28). TLR7 and TLR9 are expressed in dendritic cell (DC) subsets (high levels in plasmacytoid dendritic cells, pDCs), macrophages, and B-cells $(29,30)$. In pDCs and macrophages, TLR7/TLR9 engagement strongly promotes IFN-I production. Conversely, TLR7 expression is strongly stimulated by IFN-I. In human beings as well as mice, TLR8 is not associated with immunopathology, possibly reflecting the fact that pDCs and B-cells do not express it (28).

Endosomal TLRs play a central role in autoimmunity in spontaneous lupus models. Although IFN-I production is not directly involved in the pathogenesis of lupus-like disease in $\mathrm{MRL} / \mathrm{lpr}$ mice, anti-Sm autoantibodies are abolished in TLR7-deficient mice, whereas anti-dsDNA is TLR9-dependent $(28,31)$. Treatment with a dual TLR7/TLR9 inhibitor prevents disease progression in NZB/W mice, and there is genetic evidence that TLR7 is involved in human SLE $(32,33)$. The dependence of lupus-like disease in MRL/lpr mice on TLR7/TLR9, but not IFN-I, suggests that TLR signaling may have a role beyond the induction of IFN-I. Consistent with that possibility, TLR7/TLR9 signaling has B-cellintrinsic effects on B-cell proliferation, terminal differentiation of memory B-cells, and spontaneous germinal center formation (34).

It has become increasingly clear that the TLR7/TLR9 ligands driving IFN-I production in SLE are derived from endogenous nucleic acids. There are numerous examples of lupus-like autoimmunity in mice with defective clearance of dead cells (35), though less evidence is available that the disease is IFN-I-dependent. Cells undergoing apoptosis expose phosphatidylserine (PtdSer) on the outer leaflet of the cell membrane (36). This is recognized by a variety of receptors mediating the rapid phagocytosis and degradation of dead cells before they can release endogenous nucleic acids capable of engaging TLR7/TLR9. PtdSer on apoptotic cells is bound by MFG-E8 (a secreted protein), serum proteins (protein $S$ and Gas6), and complement component C1q. Phagocytosis of apoptotic cells coated by MFG-E8 is facilitated by the integrins $\alpha_{v} \beta_{3}$ and $\alpha_{v} \beta_{5}$, whereas uptake of cells coated with protein $S$ or Gas6 is mediated by the "TAM receptors" Tyro3, Axl, and Mertk (35), and uptake of C1q-opsonized cells is mediated by the scavenger receptor SCARF1 (37). This promotes the noninflammatory clearance of dead cells and the suppression of TLR signaling. Deficiency of Mertk or other TAM receptors in mice causes lupus-like disease manifestations, such as nephritis, arthritis, and production of anti-dsDNA autoantibodies, but not anti-Sm/RNP (38) (Table 1). The phenotype is most severe in TAM triple knockout mice, but apparent in single and double knockout animals (39). C1q-deficient mice exhibit autoantibodies, glomerular accumulation of dead cells, and nephritis (40). Similarly, the risk of lupus in C1q-deficient human beings is $93 \%$. There is considerable redundancy of the receptors utilized for clearing apoptotic cells. Although single-gene mutations frequently are associated with lupus-like phenomena, that is not always the case. For example, deficiency of the PtdSer receptor Tim-4 is not associated with lupus-like disease (41).

\section{Interferon in Human and Murine Single-Gene Lupus Models}

Mice with deletion or over-expression of certain single genes develop limited lupus-like syndromes mediated in part by IFN-I production. These disorders are associated with a limited spectrum of autoantibodies, usually only anti-DNA/chromatin, and renal immune complex deposition with or without histological changes and proteinuria (Table $\mathbf{1}$ ).

\section{BAFF-Transgenic Mice}

$\mathrm{B}$-cell survival and maturation are enhanced by transgenic (Tg) expression of B-cell activating factor of the TNF family (BAFF, also known as BLyS), which activates NF- $\mathrm{B} 2$ in B-cells (42). BAFF over-expression is seen in SLE patients as well as NZB/W and MRL/lpr mice (43). Moreover, BAFF inhibitors (TACI-Ig in mice, belimumab in human beings) reduce disease severity. Increased BAFF-TACI signaling decreases the stringency of negative selection of autoreactive B-cells in the periphery, promoting survival of autoreactive B-cells (44). BAFF-Tg mice produce high levels of anti-dsDNA and histone autoantibodies as well as rheumatoid factor, but not anti-Sm/RNP (45). Autoantibody production in these mice is $\mathrm{T}$-cell independent but requires B-cellintrinsic signals through the TLR/MyD88 pathway (45). TLR7/9 signaling strongly up-regulates expression of TACI, one of the receptors for BAFF and IFN-I stimulates BAFF expression by macrophages and dendritic cells (45). However, it is unclear whether BAFF-Tg mice exhibit the interferon signature.

Other single-gene defects affecting B-cell activation/maturation cause lupus-like disease. For example, deletion of the tyrosine kinase Lyn or over-expression of Bruton's tyrosine kinase $(B t k)$ is associated with lupus-like disease $(46,47)$. But these disorders have not been linked to dysregulated IFN-I production, suggesting that abnormalities in B-cell signaling may promote autoimmunity by IFN-I-independent mechanisms.

\section{“Interferonopathies" (TREM173, TREX1, MDA5, DNasell, and Other Defects)}

In addition to the endosomal nucleic acid sensors TLR3/TLR7/TLR8/TLR9, the cytoplasm contains sensors for DNA and RNA, the primary function of which is to detect microbial infection (48). These molecules also recognize 
endogenous nucleic acids, but in the normal state, self-DNA/RNA is sequestered away from the sensors and degraded before it can stimulate an IFN-I response $(35,49)$. However, when endogenous nucleic acid is inefficiently degraded, it can engage the sensors, resulting in interferon-mediated autoinflammatory diseases (16). In pediatric populations, screening for these disorders is carried out by testing for the interferon signature (17). Defects in genes involved in the STING pathway are an example. STING is an endoplasmic reticulum-associated protein that recognizes cytoplasmic DNA, resulting in IFN-I production via the activation of TBK1 and transcription factor IRF3 (19). Human gain of function mutations in TREM173 (encodes STING) causes an IFN-I-mediated autoinflammatory syndrome characterized by cutaneous vasculopathy and pulmonary inflammation (19). However, ANAs are not prominent and lupus-like disease develops only rarely. Similarly, human loss-of-function mutations in TREX1, a negative regulator of STING (50), cause autoinflammatory disease manifested by severe neurological impairment (encephalopathy, calcification of the basal ganglia) caused by IFN-I production in the central nervous system (Aicardi-Goutieres syndrome) (51). They also are associated with familial chilblain lupus, an erythematous/violaceous rash typically involving the hands and/or feet but distinct from the classic SLE rashes. ANAs sometimes are produced, but not anti-dsDNA or anti-Sm/RNP, and typical clinical manifestations of SLE are rare. Murine Trex1 deficiency is lethal, causing autoinflammatory disease with myocarditis and autoantibodies against cardiac muscle, but not the typical lupus autoantibodies. Interestingly, gain-of-function mutations of the cytoplasmic RNA sensor MDA5 cause an IFN-I-mediated autoinflammatory syndrome similar to disorders of the STING/TREX1 axis (52). STING paradoxically suppresses lupus-like disease in MRL/lpr mice and in pristane-induced lupus. STING-deficient mice develop accelerated glomerulonephritis and mortality and STING-deficient MRL/lpr mice develop an interferon signature (18). The exacerbation of lupus may be related to low expression of A20, SOCS1, and SOCS3, which are negative regulators of TLR signaling, in STING-deficient mice.

Abnormal endosomal degradation of DNA released by apoptotic cells by DNase II also causes an inflammatory disorder (35). DNase II deficiency is embryonic lethal, but conditional knockout mutants develop IFN-I-mediated arthritis resembling rheumatoid arthritis with low levels of anti-dsDNA autoantibodies (10\% of the level seen in MRL/lpr mice) (35). Although TLR independent, the disease is STING dependent (53).

The phenotypes of these interferonopathies illustrate an important point that while over-production of IFN-I (as indicated by the high interferon signature in such patients) is sufficient to cause autoinflammatory disease, it is not sufficient to cause lupus, possibly reflecting the synergistic effects of IFN-I over-production with delayed phagocytosis of apoptotic cells and abnormal B-cell activation/maturation. That possibility is supported by the phenotype of lupus-like disease in mice treated with pristane and by the fact that exogenous IFN $\alpha$ administration (via an adenoviral vector) is insufficient to induce lupus-like disease in non-autoimmune prone mice (22).

\section{Pristane-Induced Lupus}

Pristane (2,6,10,14-tetramethylpentadecane) is an isoprenoid alkane found in plants, shark liver, and mineral oil, a byproduct of petroleum distillation. Intraperitoneal injection of pristane in non-autoimmune prone mice, such as $\mathrm{B} 6$ or $\mathrm{BALB} / \mathrm{c}$, causes a lupus-like syndrome with high levels of IgG anti-dsDNA, anti-Sm/RNP, anti-Su, anti-ribosomal $\mathrm{P}$, and other lupus-related autoantibodies starting $\sim 3$ months after treatment (54). As in SLE patients, disease is more severe in females (55). The clinical manifestations exhibit strain-to-strain variability, and include immune complex-mediated glomerulonephritis (prominent in $\mathrm{BALB} / \mathrm{c}$ and SJL mice), arthritis (BALB/c), anemia (most strains), and diffuse alveolar hemorrhage (DAH, B6, and B10 mice) (54, 56) (Table 1). Many of these manifestations are cytokine driven.

Like SLE patients, pristane-treated mice exhibit a strong IFN signature and mice deficient in the IFNAR do not develop autoantibodies or glomerulonephritis (54). In contrast, anemia in pristane-treated mice is dependent on TNF $\alpha$ and independent of IFN-I. The bone marrow of pristane-treated mice shows high levels of TNF $\alpha$ and a remarkable accumulation of apoptotic cells, abnormalities that are also present in the bone marrow of SLE patients (57). The arthritis in pristane-treated mice also is likely to be TNF $\alpha$ mediated as it is ameliorated by TNF inhibitor therapy (58). IFN-I and TNF $\alpha$ production is TLR7 dependent (57, 59). Nephritis and anemia are abolished in TLR7-deficient mice, but not in TLR9-deficient mice. Interestingly, the production of autoantibodies against RNA-protein antigens is TLR7 dependent, but so is production of anti-dsDNA autoantibodies. Pristane treatment causes the accumulation of dead cells in the bone marrow and other sites (57), which are likely to be the source of endogenous TLR7 ligands driving the disease. Pristane induces lupus in germ-free mice, emphasizing the probable role of endogenous rather than microbial TLR7 ligands in disease pathogenesis (60).

\section{IFN-I Production in Pristane-Induced Lupus}

Although pristane-treated mice exhibit a robust IFN signature and autoantibody production and nephritis are abolished in IFNAR-deficient mice, the role of IFN-I in disease pathogenesis is incompletely understood. A population of inflammatory $\left(\mathrm{Ly} 6 \mathrm{C}^{\mathrm{hi}}\right)$ monocytes produces most of the IFN-I in pristane-treated mice (61), although smaller amounts are produced by pDCs. Paradoxically, although wild-type B6 mice develop both autoantibodies and an interferon signature, Fas-deficient (B6/lpr) mice are refractory to the induction of autoantibodies by pristane despite exhibiting an interferon signature (62). The explanation is under investigation.

\section{Conclusion}

Animal models have led to a clearer understanding of the role of IFN-I in the pathogenesis of lupus-like disease. One major effect of IFN-I over-production is enhanced TLR7 expression and TLR7 signaling, which may maintain IFN-I production as well as having intrinsic effects on B-cell activation and maturation. However, as illustrated by the interferonopathies, over-production of IFNI, although pro-inflammatory, does not suffice to induce lupuslike disease. The pristane-lupus model suggests that the lupus 
phenotype depends on more than just IFN-I. TNF $\alpha$ influences the pathogenesis of some of the clinical manifestations (e.g., anemia, arthritis), whereas others are independent of both TNF $\alpha$ and IFNI (e.g., DAH). By activating multiple inflammatory pathways as well as promoting the accumulation of apoptotic cells/endogenous TLR7 ligands and B-cell activation, the inducible pristane-lupus model may afford a window into the roles played by the multiple

\section{References}

1. Arbuckle MR, McClain MT, Rubertone MV, Scofield RH, Dennis GJ, James JA, et al. Development of autoantibodies before the clinical onset of systemic lupus erythematosus. N Engl J Med. (2003) 349(16):1526-33. doi:10.1056/ NEJMoa021933

2. Tan EM, Cohen AS, Fries JF, Masi AT, McShane DJ, Rothfield NF, et al. The 1982 revised criteria for the classification of systemic lupus erythematosus. Arthritis Rheum (1982) 25:1271-7. doi:10.1002/art.1780251101

3. Baechler EC, Batliwalla FM, Karypis G, Gaffney PM, Ortmann WA, Espe KJ, et al. Interferon-inducible gene expression signature in peripheral blood cells of patients with severe lupus. Proc Natl Acad Sci U S A. (2003) 100(5):2610-5. doi:10.1073/pnas.0337679100

4. Bennett L, Palucka AK, Arce E, Cantrell V, Borvak J, Banchereau J, et al. Interferon and granulopoiesis signatures in systemic lupus erythematosus blood. $J$ Exp Med. (2003) 197(6):711-23. doi:10.1084/jem.20021553

5. Zhuang H, Narain S, Sobel E, Lee PY, Nacionales DC, Kelly KM, et al. Association of anti-nucleoprotein autoantibodies with upregulation of Type I interferon-inducible gene transcripts and dendritic cell maturation in systemic lupus erythematosus. Clin Immunol. (2005) 117(3):238-50. doi:10.1016/j.clim. 2005.07.009

6. Kirou KA, Lee C, George S, Louca K, Peterson MG, Crow MK. Activation of the interferon-alpha pathway identifies a subgroup of systemic lupus erythematosus patients with distinct serologic features and active disease. Arthritis Rheum (2005) 52(5):1491-503. doi:10.1002/art.21031

7. Dallera MC, Cardarelli PM, Preston BT, Witte A, Davis JC Jr. Type I interferon correlates with serological and clinical manifestations of SLE. Ann Rheum Dis. (2005) 64(12):1692-7. doi:10.1136/ard.2004.033753

8. Harley IT, Kaufman KM, Langefeld CD, Harley JB, Kelly JA. Genetic susceptibility to SLE: new insights from fine mapping and genome-wide association studies. Nat Rev Genet. (2009) 10(5):285-90. doi:10.1038/nrg2571

9. Niewold TB, Kelly JA, Kariuki SN, Franek BS, Kumar AA, Kaufman KM, et al. IRF5 haplotypes demonstrate diverse serological associations which predict serum interferon alpha activity and explain the majority of the genetic association with systemic lupus erythematosus. Ann Rheum Dis. (2012) 71(3):463-8. doi:10.1136/annrheumdis-2011-200463

10. Watts RA. Musculoskeletal and systemic reactions to biological therapeutic agents. Curr Opin Rheumatol. (2000) 12(1):49-52.

11. Zhuang H, Kosboth M, Lee P, Rice A, Driscoll DJ, Zori R, et al. Lupus-like disease and high interferon levels with trisomy of the Type I interferon cluster on chromosome 9p. Arthritis Rheum (2006) 54(5):1573-9. doi:10.1002/art. 21800

12. Santiago-Raber ML, Baccala R, Haraldsson KM, Choubey D, Stewart TA, Kono $\mathrm{DH}$, et al. Type-I interferon receptor deficiency reduces lupus-like disease in NZB mice. J Exp Med. (2003) 197(6):777-88. doi:10.1084/jem.20021996

13. Nacionales DC, Kelly-Scumpia KM, Lee PY, Weinstein JS, Sobel E, Satoh $\mathrm{M}$, et al. Deficiency of the Type I interferon receptor protects mice from experimental lupus. Arthritis Rheum (2007) 56:3770-83. doi:10.1002/art.23023

14. Okanoue T, Sakamoto S, Itoh Y, Minami M, Yasui K, Sakamoto M, et al. Side effects of high-dose interferon therapy for chronic hepatitis C. J Hepatol. (1996) 25(3):283-91. doi:10.1016/S0168-8278(96)80113-9

15. Lauwerys BR, Ducreux J, Houssiau FA. Type I interferon blockade in systemic lupus erythematosus: where do we stand? Rheumatology (Oxford). (2014) 53(8):1369-76. doi:10.1093/rheumatology/ket403

16. Crow YJ, Casanova JL. STING-associated vasculopathy with onset in infancy a new interferonopathy. $N$ Engl J Med. (2014) 371(6):568-71. doi:10.1056/ NEJMe1407246 pathways shaping the widely variable phenotypes of SLE in different patients.

\section{Acknowledgments}

Supported by research grants from NIH/NIAMS (R01-AR44731) and the Lupus Research Institute.

17. Rice GI, Forte GM, Szynkiewicz M, Chase DS, Aeby A, Abdel-Hamid MS, et al. Assessment of interferon-related biomarkers in Aicardi-Goutieres syndrome associated with mutations in TREX1, RNASEH2A, RNASEH2B, RNASEH2C, SAMHD1, and ADAR: a case-control study. Lancet Neurol. (2013) 12(12):1159-69. doi:10.1016/S1474-4422(13)70258-8

18. Sharma S, Campbell AM, Chan J, Schattgen SA, Orlowski GM, Nayar R, et al. Suppression of systemic autoimmunity by the innate immune adaptor STING. Proc Natl Acad Sci U S A. (2015) 112(7):E710-7. doi:10.1073/pnas. 1420217112

19. Liu Y, Jesus AA, Marrero B, Yang D, Ramsey SE, Montealegre Sanchez GA, et al. Activated STING in a vascular and pulmonary syndrome. N Engl J Med. (2014) 371(6):507-18. doi:10.1056/NEJMoa1312625

20. Hron JD, Peng SL. Type I IFN protects against murine lupus. J Immunol. (2004) 173(3):2134-42. doi:10.4049/jimmunol.173.3.2134

21. Morel L, Croker BP, Blenman KR, Mohan C, Huang G, Gilkeson G, et al. Genetic reconstitution of systemic lupus erythematosus immunopathology with polycongenic murine strains. Proc Natl Acad Sci U S A. (2000) 97(12):6670-5. doi:10.1073/pnas.97.12.6670

22. Mathian A, Weinberg A, Gallegos M, Banchereau J, Koutouzov S. IFN-alpha induces early lethal lupus in preautoimmune (New Zealand Black x New Zealand White) F1 but not in BALB/c mice. J Immunol. (2005) 174(5):2499-506. doi:10.4049/jimmunol.174.5.2499

23. Braun D, Geraldes P, Demengeot J. Type I Interferon controls the onset and severity of autoimmune manifestations in lpr mice. J Autoimmun. (2003) 20(1):15-25. doi:10.1016/S0896-8411(02)00109-9

24. Pisitkun P, Deane JA, Difilippantonio MJ, Tarasenko T, Satterthwaite AB, Bolland S. Autoreactive B cell responses to RNA-related antigens due to TLR7 gene duplication. Science (2006) 312(5780):1669-72. doi:10.1126/science. 1124978

25. Subramanian S, Tus K, Li QZ, Wang A, Tian XH, Zhou J, et al. A Tlr7 translocation accelerates systemic autoimmunity in murine lupus. Proc Natl Acad Sci U S A (2006) 103(26):9970-5. doi:10.1073/pnas.0603912103

26. Deane JA, Pisitkun P, Barrett RS, Feigenbaum L, Town T, Ward JM, et al Control of toll-like receptor 7 expression is essential to restrict autoimmunity and dendritic cell proliferation. Immunity (2007) 27(5):801-10. doi:10.1016/j. immuni.2007.09.009

27. Kawai T, Akira S. TLR signaling. Semin Immunol. (2007) 19(1):24-32. doi:10 1016/j.smim.2006.12.004

28. Ewald SE, Barton GM. Nucleic acid sensing Toll-like receptors in autoimmunity. Curr Opin Immunol. (2011) 23(1):3-9. doi:10.1016/j.coi.2010.11.006

29. Gilliet M, Cao W, Liu YJ. Plasmacytoid dendritic cells: sensing nucleic acids in viral infection and autoimmune diseases. Nat Rev Immunol. (2008) 8(8):594-606. doi:10.1038/nri2358

30. Iwasaki A, Medzhitov R. Toll-like receptor control of the adaptive immune responses. Nat Immunol. (2004) 5(10):987-95. doi:10.1038/ni1112

31. Christensen SR, Shupe J, Nickerson K, Kashgarian M, Flavell RA, Shlomchik MJ. Toll-like receptor 7 and TLR9 dictate autoantibody specificity and have opposing inflammatory and regulatory roles in a murine model of lupus. Immunity (2006) 25(3):417-28. doi:10.1016/j.immuni.2006.07.013

32. Barrat FJ, Meeker T, Chan JH, Guiducci C, Coffman RL. Treatment of lupusprone mice with a dual inhibitor of TLR7 and TLR9 leads to reduction of autoantibody production and amelioration of disease symptoms. Eur J Immunol. (2007) 37(12):3582-6. doi:10.1002/eji.200737815

33. Shen N, Fu Q, Deng Y, Qian X, Zhao J, Kaufman KM, et al. Sex-specific association of X-linked Toll-like receptor 7 (TLR7) with male systemic lupus erythematosus. Proc Natl Acad Sci U S A (2010) 107(36):15838-43. doi:10.1073/ pnas. 1001337107 
34. Hou B, Saudan P, Ott G, Wheeler ML, Ji M, Kuzmich L, et al. Selective utilization of Toll-like receptor and MyD88 signaling in B cells for enhancement of the antiviral germinal center response. Immunity (2011) 34(3):375-84. doi:10.1016/ j.immuni.2011.01.011

35. Nagata S, Hanayama R, Kawane K. Autoimmunity and the clearance of dead cells. Cell (2010) 140(5):619-30. doi:10.1016/j.cell.2010.02.014

36. Henson PM, Bratton DL, Fadok VA. Apoptotic cell removal. Curr Biol. (2001) 11(19):R795-805. doi:10.1016/S0960-9822(01)00474-2

37. Ramirez-Ortiz ZG, Pendergraft WF III, Prasad A, Byrne MH, Iram T, Blanchette CJ, et al. The scavenger receptor SCARF1 mediates the clearance of apoptotic cells and prevents autoimmunity. Nat Immunol. (2013) 14(9):917-26. doi:10.1038/ni.2670

38. Lu Q, Lemke G. Homeostatic regulation of the immune system by receptor tyrosine kinases of the Tyro 3 family. Science (2001) 293(5528):306-11. doi:10. 1126/science.1061663

39. Tibrewal N, Wu Y, D’mello V, Akakura R, George TC, Varnum B, et al. Autophosphorylation docking site Tyr-867 in Mer receptor tyrosine kinase allows for dissociation of multiple signaling pathways for phagocytosis of apoptotic cells and down-modulation of lipopolysaccharide-inducible NF-kappaB transcriptional activation. J Biol Chem. (2008) 283(6):3618-27. doi:10.1074/jbc.M706906200

40. Crispin JC, Hedrich CM, Tsokos GC. Gene-function studies in systemic lupus erythematosus. Nat Rev Rheumatol. (2013) 9(8):476-84. doi:10.1038/nrrheum. 2013.78

41. Wong K, Valdez PA, Tan C, Yeh S, Hongo JA, Ouyang W. Phosphatidylserine receptor Tim-4 is essential for the maintenance of the homeostatic state of resident peritoneal macrophages. Proc Natl Acad Sci U S A. (2010) 107(19):8712-7. doi:10.1073/pnas.0910929107

42. Gardam S, Brink R. Non-canonical NF-kappaB signaling initiated by BAFF influences B cell biology at multiple junctures. Front Immunol. (2014) 4:509. doi:10.3389/fimmu.2013.00509

43. Mackay F, Schneider P. Cracking the BAFF code. Nat Rev Immunol. (2009) 9(7):491-502. doi:10.1038/nri2572

44. Rawlings DJ, Schwartz MA, Jackson SW, Meyer-Bahlburg A. Integration of $\mathrm{B}$ cell responses through Toll-like receptors and antigen receptors. Nat Rev Immunol. (2012) 12(4):282-94. doi:10.1038/nri3190

45. Groom JR, Fletcher CA, Walters SN, Grey ST, Watt SV, Sweet MJ, et al. BAFF and MyD88 signals promote a lupuslike disease independent of T cells. J Exp Med. (2007) 204(8):1959-71. doi:10.1084/jem.20062567

46. Lamagna C, Hu Y, DeFranco AL, Lowell CA. B cell-specific loss of Lyn kinase leads to autoimmunity. J Immunol. (2014) 192(3):919-28. doi:10.4049/ jimmunol.1301979

47. Kil LP, de Bruijn MJ, van Nimwegen M, Corneth OB, van Hamburg JP, Dingjan GM, et al. Btk levels set the threshold for B-cell activation and negative selection of autoreactive B cells in mice. Blood (2012) 119(16):3744-56. doi:10.1182/ blood-2011-12-397919

48. Desmet CJ, Ishii KJ. Nucleic acid sensing at the interface between innate and adaptive immunity in vaccination. Nat Rev Immunol. (2012) 12(7):479-91. doi:10.1038/nri3247

49. Barton GM, Kagan JC. A cell biological view of Toll-like receptor function: regulation through compartmentalization. Nat Rev Immunol. (2009) 9(8):535-42. doi: $10.1038 /$ nri2587

50. Gall A, Treuting P, Elkon KB, Loo YM, Gale M Jr, Barber GN, et al. Autoimmunity initiates in nonhematopoietic cells and progresses via lymphocytes in an interferon-dependent autoimmune disease. Immunity (2012) 36(1):120-31. doi:10.1016/j.immuni.2011.11.018

51. Rice G, Newman WG, Dean J, Patrick T, Parmar R, Flintoff K, et al. Heterozygous mutations in TREX1 cause familial chilblain lupus and dominant Aicardi-Goutieres syndrome. Am J Hum Genet. (2007) 80(4):811-5. doi:10. $1086 / 513443$

52. Rice GI, del Toro Duany Y, Jenkinson EM, Forte GM, Anderson BH, Ariaudo G, et al. Gain-of-function mutations in IFIH1 cause a spectrum of human disease phenotypes associated with upregulated type I interferon signaling. Nat Genet. (2014) 46(5):503-9. doi:10.1038/ng.2933

53. Ahn J, Gutman D, Saijo S, Barber GN. STING manifests self DNA-dependent inflammatory disease. Proc Natl Acad Sci U S A. (2012) 109(47):19386-91. doi:10.1073/pnas.1215006109

54. Reeves WH, Lee PY, Weinstein JS, Satoh M, Lu L. Induction of autoimmunity by pristane and other naturally occurring hydrocarbons. Trends Immunol (2009) 30(9):455-64. doi:10.1016/j.it.2009.06.003

55. Smith DL, Dong X, Du S, Oh M, Singh RR, Voskuhl RR. A female preponderance for chemically induced lupus in SJL/J mice. Clin Immunol. (2007) 122(1):101-7. doi:10.1016/j.clim.2006.09.009

56. Chowdhary VR, Grande JP, Luthra HS, David CS. Characterization of haemorrhagic pulmonary capillaritis: another manifestation of pristane-induced lupus. Rheumatology (Oxford). (2007) 46:1405-10. doi:10.1093/rheumatology/ kem 117

57. Zhuang H, Han S, Xu Y, Li Y, Wang H, Yang LJ, et al. Toll-like receptor 7stimulated tumor necrosis factor alpha causes bone marrow damage in systemic lupus erythematosus. Arthritis Rheumatol. (2014) 66(1):140-51. doi:10.1002/ art.38189

58. Beech JT, Thompson SJ. Anti-tumour necrosis factor therapy ameliorates joint disease in a chronic model of inflammatory arthritis. Br J Rheumatol. (1997) 36(10):1129.

59. Lee PY, Kumagai Y, Li Y, Takeuchi O, Yoshida H, Weinstein J, et al. TLR7dependent and FcgammaR-independent production of type I interferon in experimental mouse lupus. J Exp Med. (2008) 205(13):2995-3006. doi:10.1084/ jem.20080462

60. Mizutani A, Shaheen VM, Yoshida H, Akaogi J, Kuroda Y, Nacionales DC, et al. Pristane-induced autoimmunity in germ-free mice. Clin Immunol. (2005) 114(2):110-8. doi:10.1016/j.clim.2004.09.010

61. Lee PY, Weinstein JS, Nacionales DC, Scumpia PO, Li Y, Butfiloski E, et al A novel type I IFN-producing cell subset in murine lupus. J Immunol. (2008) 180(7):5101-8. doi:10.4049/jimmunol.180.7.5101

62. Satoh M, Weintraub JP, Yoshida H, Shaheen VM, Richards HB, Shaw M, et al Fas and Fas ligand mutations inhibit autoantibody production in pristaneinduced lupus. J Immunol. (2000) 165:1036-43. doi:10.4049/jimmunol.165.2. 1036

Conflict of Interest Statement: The authors declare that the research was conducted in the absence of any commercial or financial relationships that could be construed as a potential conflict of interest.

Copyright (c) 2015 Zhuang, Szeto, Han, Yang and Reeves. This is an open-access article distributed under the terms of the Creative Commons Attribution License (CC $B Y)$. The use, distribution or reproduction in other forums is permitted, provided the original author(s) or licensor are credited and that the original publication in this journal is cited, in accordance with accepted academic practice. No use, distribution or reproduction is permitted which does not comply with these terms. 